\title{
Groundwater Vulnerability for the Surface Outcropping Aquifers in Jordan
}

\author{
Alsharifa Hind Mohammad1, Thair Almomani'2, Ikhlas Alhejoj1 \\ ${ }^{1}$ Water, Energy and Environment Center, The University of Jordan, Amman, Jordan \\ ${ }^{2}$ Ministry of Water and Irrigation, Amman, Jordan \\ Email: s.jasem@ju.edu.jo
}

Received 3 March 2015; accepted 17 March 2015; published 19 March 2015

Copyright (C) 2015 by authors and Scientific Research Publishing Inc.

This work is licensed under the Creative Commons Attribution International License (CC BY). http://creativecommons.org/licenses/by/4.0/

(c) (i) Open Access

\begin{abstract}
Groundwater vulnerability is an overlay method that is used to determine the ability of pollutants to penetrate to the target aquifer and to harm it. This method helps decision makers by shedding light on pollution areas expected to pollute groundwater aquifers as caused by human activities on the ground surface. In Jordan, groundwater is the main water resource the country uses to match its demand. The groundwater basins in Jordan are divided into 12 major basins. Some basins are rechargeable and other basins are fossil. Many basins are over exploited. Amman Zarqa basin is a clear example for this case. Others are saline just like Azraq basin and the rest is expected to be affected by the growing demand for agricultural, municipal and industrial activities. In this study, a groundwater vulnerability map was produced for Jordan using DRASTIC index to study the vulnerability of the shallow aquifers throughout the country. The map shows different vulnerability classes ranging from low to very high reflecting the environmental, hydrological and hydrogeological settings of the groundwater and its recharge ability. The resulted map shows wide variation in groundwater vulnerability in different sites in Jordan. Areas with higher vulnerability are those with friable aquifer materials and shallow groundwater depths. Medium and low vulnerability classes are exist too because of the variations of the environmental settings within the targeted areas.
\end{abstract}

\section{Keywords}

Groundwater, Vulnerability, Aquifers, Vadose Zone, Jordan

\section{Introduction}

Water supply is one of the main national concerns of Jordan that results from its limited water resources. The 
country was classified as one of the poorest countries in water resources worldwide [1].

The concept of groundwater vulnerability was introduced in the 1960s in France by Margat (1968) [2]. Since then, several approaches for developing aquifer vulnerability maps were developed such as DRASTIC [3], GOD [4], AVI [5], and SINTACS [6]. The conventional methods such as DRASTIC, AVI, GOD and SINTACS could distinguish degrees of vulnerability on a regional scale involving different lithologies [7]. DRASTIC was a familiar method developed for the US Environmental Protection Agency (EPA) by Aller et al. (1987) [3] and it had been used in different regions worldwide with satisfactory results [8]-[16].

This article discusses the vulnerability of the shallow aquifers in Jordan using DRASTIC index; this index incorporates the different hydrological factors such as rainfall, depth to the groundwater table, hydraulic conductivity and other factors including topography, recharge ability and amounts, aquifer media and vadose zone effects which naturally participate in protecting aquifers.

Jordan is an arid to semi-arid country, with a land area of approximately $90,000 \mathrm{~km}^{2}$. The mean annual rainfall in Jordan ranges between $50 \mathrm{~mm}$ in the southern desert region to about $600 \mathrm{~mm}$ along the western mountains adjacent to the Jordan Valley. As a result of increasing population pressure in recent years, Jordan has needed to increment exploitation of its natural resources as well as to protect the environment. Therefore, the demand for high quality drinking water is increasing, knowing that the average household water consumption is about 80 liters/capita/day which is one of the lowest rates worldwide compared to the living standards in Jordan [17].

Groundwater is considered to be the major water supply source for many areas, and is the only water resource in some others. It can be divided into renewable and non-renewable groundwater resources. The main groundwater bodies are found in bedrock aquifers, and they form the main groundwater sources. The main aquifers are composed of sandstone like Kurnub and Ram groups, the carbonate aquifers like Amman Silicified Limestone A7/B2 and Belqa B4/B5 group, in addition to the basalt aquifer.

Unconsolidated aquifers, like fluvial deposits in the Jordan Valley, are compared to the bedrock aquifers of minor importance.

On a regional scale, the aquifers in Jordan can be grouped into three major aquifer systems, classified by their spatial distribution, lithology and age of the geological units.

These aquifer systems are:

1) Deep Aquifer Complex: it includes Ram aquifer, Khreim aquitard, Zarqa aquifer and Kurnub aquifer.

2) Intermediate Aquifer Complex: it includes A1/2 semi aquifer, A3 aquitard, A4 aquifer, A5/6 aquitard and B2/A7 aquifer.

3) Shallow Aquifer Complex: it includes B3 aquitard, B4/5 aquifer, basalt aquifer and alluvial deposits [18].

\section{Methodology}

For building the groundwater vulnerability map, different environmental parameters interfere and participate to define the amount and location of impurities that may affect the aquifers such as; groundwater settings, hydrological and hydrogeological conditions, landuse parameters, environmental issues, soil parameters and other elements which may vary from one aquifer to other and from one area to another. These parameters are used to determine the vulnerability of groundwater [19]. The different spatial parameters of the aquifer (geology, recharge, water table, soil texture, etc.) are then exported into GIS, where equations for calculating groundwater vulnerability are used to deduce different vulnerability classes.

DRASTIC index for example is one of the vulnerability indices that could be applied in Jordan because of its applicability to Jordan's climate conditions, aquifer distribution and aquifers setting. Therefore, DRASTIC was chosen for this study In addition, DRASTIC index has wide variations of parameters that are really affecting the groundwater system in different environments. In this model (DRASTIC), spatial datasets on: Depth to groundwater, Recharge by rainfall, Aquifer type, Soil properties, Topography, Impact of the vadose zone and the hydraulic Conductivity of the aquifer are combined to assess the vulnerability of aquifers to surface activities (Table 1), [20]. The governing equation of the DRASTIC index DI was defined by Knox et al., (1993) [21]; Fortin et al., (1997) [22]; and Fritch et al., (2000) [23]; is:

$$
\mathrm{DI}=\mathrm{DrDw}+\mathrm{RrRw}+\mathrm{ArAw}+\mathrm{SrSw}+\mathrm{TrTw}+\mathrm{IrIw}+\mathrm{CrCw}
$$

where DI is the DRASTIC Index, Dr is the rate of the D factor and Dw is the weight of the D factor, $\mathrm{Rr}$ is the rate for the Recharge factor and Rw is the weight for the Recharge factor, Ar is the rate for the Aquifer media factor and the Aw is the weight to the Aquifer media factor, $\mathrm{Sr}$ is the rate to the Soil media factor and Sw is the 
Table 1. Parameter's classification for the use of DRASTIC index. [3].

\begin{tabular}{|c|c|c|c|}
\hline Parameter & Range & Rating & Relative weighting \\
\hline \multirow{7}{*}{ Depth to water (D) } & $0-2 \mathrm{~m}$ & 7 & \multirow{7}{*}{5} \\
\hline & $2-5 m$ & 6 & \\
\hline & $5-9 m$ & 5 & \\
\hline & $9-15 m$ & 4 & \\
\hline & $15-23 m$ & 3 & \\
\hline & $23-30 m$ & 2 & \\
\hline & $>30 \mathrm{~m}$ & 1 & \\
\hline \multirow{7}{*}{ recharge by rainfall } & 3 & 1 & \multirow{7}{*}{4} \\
\hline & 4 & 2 & \\
\hline & 5 & 3 & \\
\hline & 6 & 4 & \\
\hline & 7 & 5 & \\
\hline & 8 & 6 & \\
\hline & 9 & 7 & \\
\hline \multirow{9}{*}{ Aquifer media (A) } & Massive shale & 2 & \multirow{9}{*}{3} \\
\hline & Metamorphic/igneous & 3 & \\
\hline & Weathered met./igneous & 4 & \\
\hline & Bedded sandstone, limestone & 6 & \\
\hline & Shale sequences & 6 & \\
\hline & Massive sandstone & 6 & \\
\hline & Massive limestone & 6 & \\
\hline & Sand and gravel & 8 & \\
\hline & Basalt & 9 & \\
\hline \multirow{11}{*}{ Soil media (S) } & Karst limestone & 10 & \multirow{11}{*}{2} \\
\hline & Soil thin or absent & 10 & \\
\hline & Gravel & 9 & \\
\hline & Sand & 8 & \\
\hline & Peat & 7 & \\
\hline & Shrinking and/or aggregated clay & 4 & \\
\hline & Sandy loam & 5 & \\
\hline & Loam silty loam & 4 & \\
\hline & Clay loam & 3 & \\
\hline & Muck & 2 & \\
\hline & Non-shrinking and non-aggregated clay & 1 & \\
\hline \multirow{6}{*}{ Topography (T) } & $0 \%-2 \%$ & 7 & \multirow{6}{*}{1} \\
\hline & $2 \%-6 \%$ & 6 & \\
\hline & $6 \%-10 \%$ & 5 & \\
\hline & $10 \%-16 \%$ & 3 & \\
\hline & $16 \%-25 \%$ & 2 & \\
\hline & $>25 \%$ & 1 & \\
\hline \multirow{11}{*}{ Impact of vadose zone } & Confining layer & 1 & \multirow{11}{*}{5} \\
\hline & Silt/clay & 3 & \\
\hline & Shale & 3 & \\
\hline & Limestone & 6 & \\
\hline & Sandstone & 6 & \\
\hline & Bedded limestone, sandstone shale & 6 & \\
\hline & Sand and gravel with significant silt \& clay & 6 & \\
\hline & Metamorphic/igneous & 4 & \\
\hline & Sand and gravel & 8 & \\
\hline & Vesicular basalt & 9 & \\
\hline & Karst limestone & 10 & \\
\hline
\end{tabular}




\section{Continued}

\begin{tabular}{|c|c|c|c|}
\hline \multirow{6}{*}{ Hydraulic conductivity } & $0.50 \times 10^{-6}-0.50 \times 10^{-4}$ & 1 & \multirow{6}{*}{3} \\
\hline & $0.50 \times 10^{-4}-0.15 \times 10^{-3}$ & 2 & \\
\hline & $0.15 \times 10^{-3}-0.36 \times 10^{-3}$ & 4 & \\
\hline & $0.36 \times 10^{-3}-0.51 \times 10^{-3}$ & 6 & \\
\hline & $0.51 \times 10^{-3}-0.10 \times 10^{-2}$ & 8 & \\
\hline & $>0.10 \times 10^{-2}$ & 10 & \\
\hline
\end{tabular}

weight to this factor, the Tr is the rate to the Topography factor and the Tw is the weight to that factor, Ir is the rate of the impact of the vadose zone rate and Iw is the weight, and finally the $\mathrm{Cr}$ is the rate for the hydraulic Conductivity rate and the $\mathrm{Cw}$ is the weight to this factor; this DRASTIC index given in the equation above is considered as an indicator for pollution potential. The effects of the different parameters on the groundwater vulnerability were described by Piscopo (2001) [24] and are shortly described below.

For the first factor, Depth to water table (D); this factor is obtained for each outcropping aquifer using borehole data that contains information about the static water level from the monitoring of water wells available in the study area (Ministry of Water and Irrigation MWI). The D factor reflects the distance between the ground surface and the groundwater table; the depth of the water table reflects the safer condition to the pollution. For the depth to water table in Jordan, the resulting map is shown in Figure 1. The figure shows that along the western escarpments the shallower depth to water table is present which reflects the higher vulnerability values of these areas.

The second factor which is the (R) factor reflects the recharge rates and amounts in the targeted area. This factor is estimated as recharge from rainfall, which means that the recharge is affected by the amounts of the rainfall, the topography of the ground surface and finally the soil type and the porosity and permeability of the soils and rocks. Data from the Department of Meteorology (DOM in addition to the digital elevation model (DEM) to determine the slope of the land surface, and finally data from the Ministry of Agriculture to define soil types were used to find out the recharge factor in the area. In Jordan; the recharge values vary as shown in Figure 2 because of the wide variation in rainfall amounts in addition to the slope and soil components.

Geological maps from Natural Resources Authority, in addition to well logs and geologic cross sections were used to determine the third factor which is the aquifer media factor. The different aquifer types were considered and their outcrops over all Jordan were delineated in a map which shows the wide variations of this factor. The (A) factor map values ranged from 6 to 9 according to the type of the aquifer as shown in Figure 3, the value of 9 goes to the Bazalt aquifer type which is a high vulnerability rock type in the DRASTIC scale, then the lowest value 6 goes to the limestone aquifer across the study area .

Soil media (S), the fourth factor reflects the soils that cover the targeted areas, soils with high permeability permit the pollutants much easier than soils with low or no permeability that is reason for including this factor in this index. Soil media maps show a variation values from 2 to 10 depending on the soil types, the 10 reflects the high porosity and permeability soils which contains sand sized that and the lowest 2 value is for the soils that contain clay sized particles which lowering the ability of the water to be move through this soil type. Figure 4 shows the map for soil factor distribution.

The topography factor $(\mathrm{T})$ depends on the slope setting of the surface of the ground which reflects the ability of pollutants to reach the groundwater according to the time needed for the water to infiltrate. Steep slopes are much safe than the gentle slopes. Figure 5 shows the wide variation of the topography in Jordan as slop percentages.

The Impact of the vadose zone factor (I) factor, this vulnerability factor is for the rocks above the aquifer, in this case where the article is about the outcropped aquifers which means that there are no layers over that targeted aquifers then the result is given to the higher I factor rate because of the absence of the protection layer here.

The last factor which is the hydraulic Conductivity factor (C) reflects the speed of the pollutants during its movement through the rock itself. Data are collected from MWI reports about transmisivity of aquifers. They were digitized in order to obtain the vulnerability.

\section{Results}

Applying the equation of the weights and rates for DRATIC index for the natural setting in Jordan which in- 


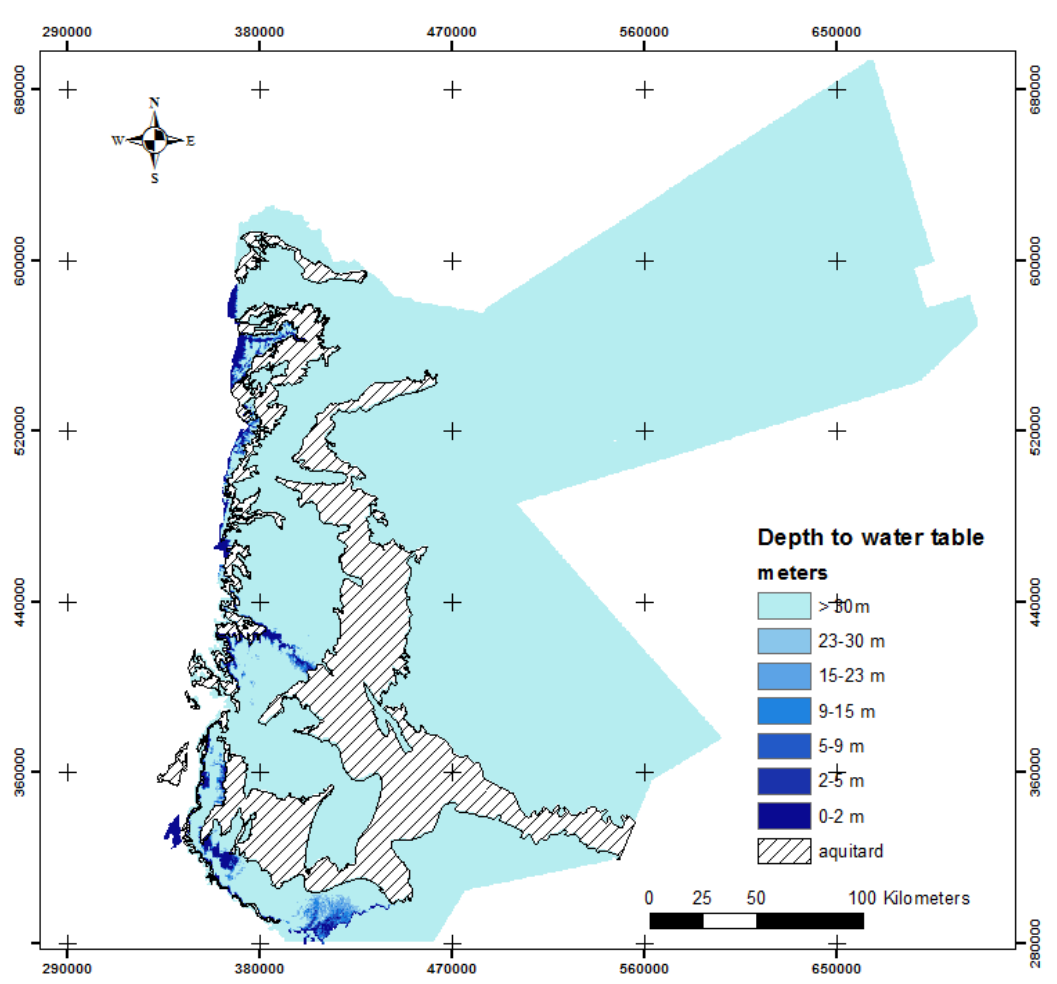

Figure 1. Depth to groundwater table (m) for the outcropping rocks in Jordan.

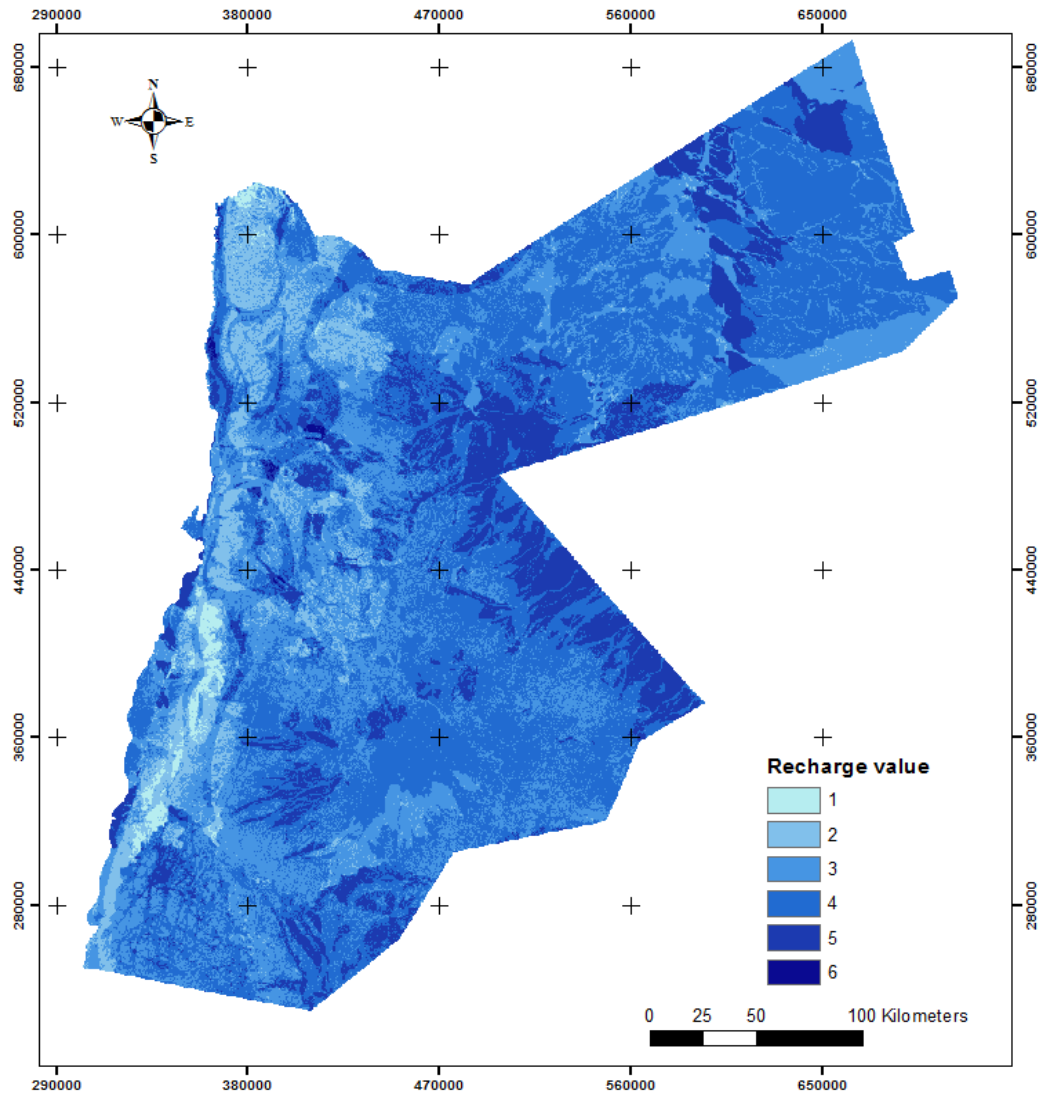

Figure 2. Recharge factor values for the outcropping rocks in Jordan. 


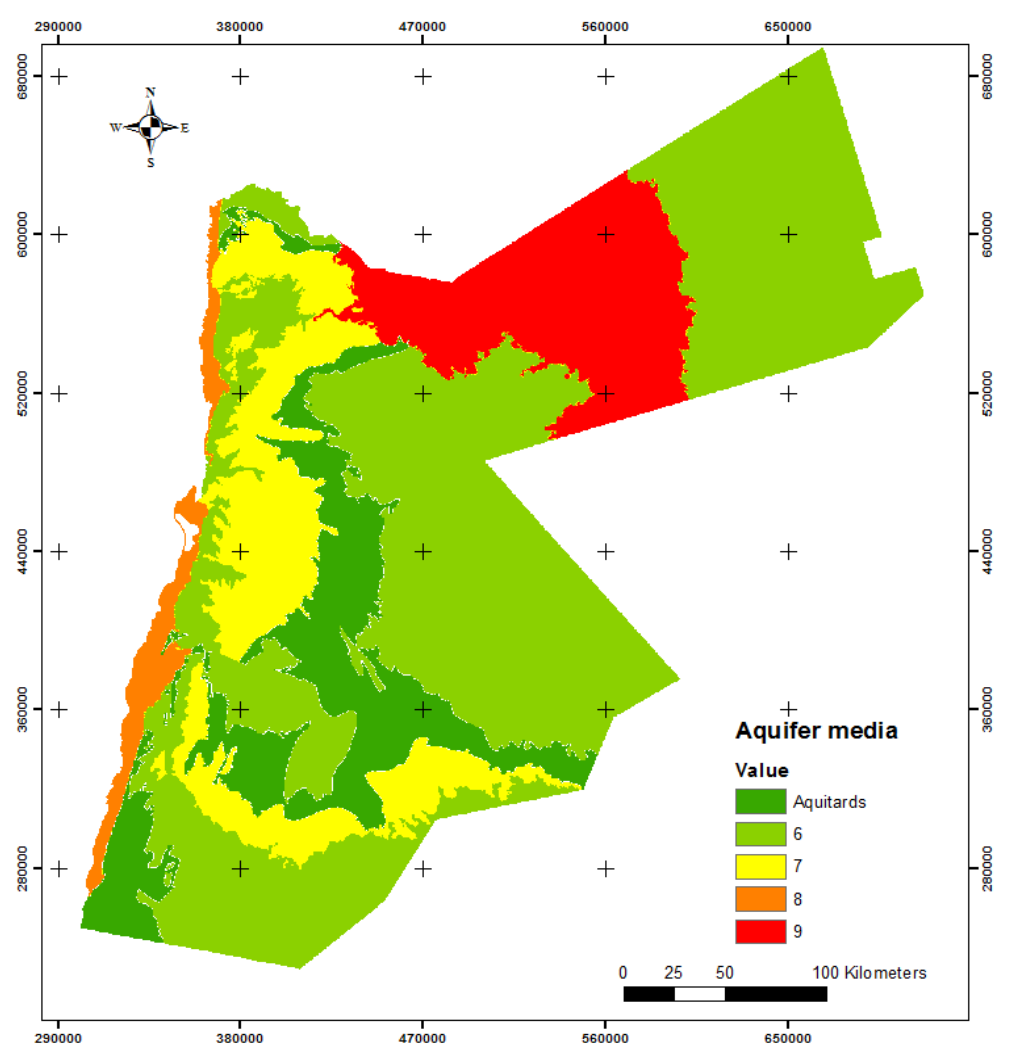

Figure 3. Aquifer media factor values for the outcropping rocks in Jordan.

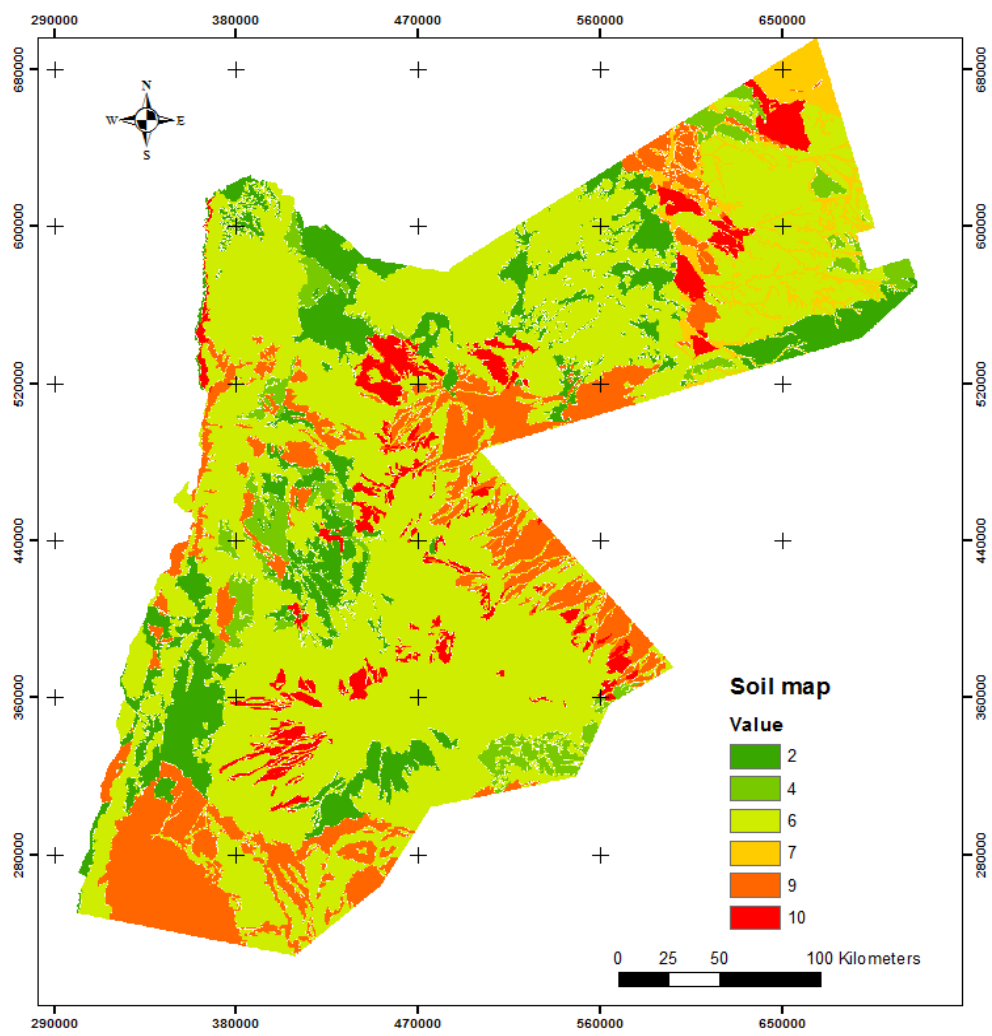

Figure 4. Soil factor values for the outcropping rocks in Jordan. 


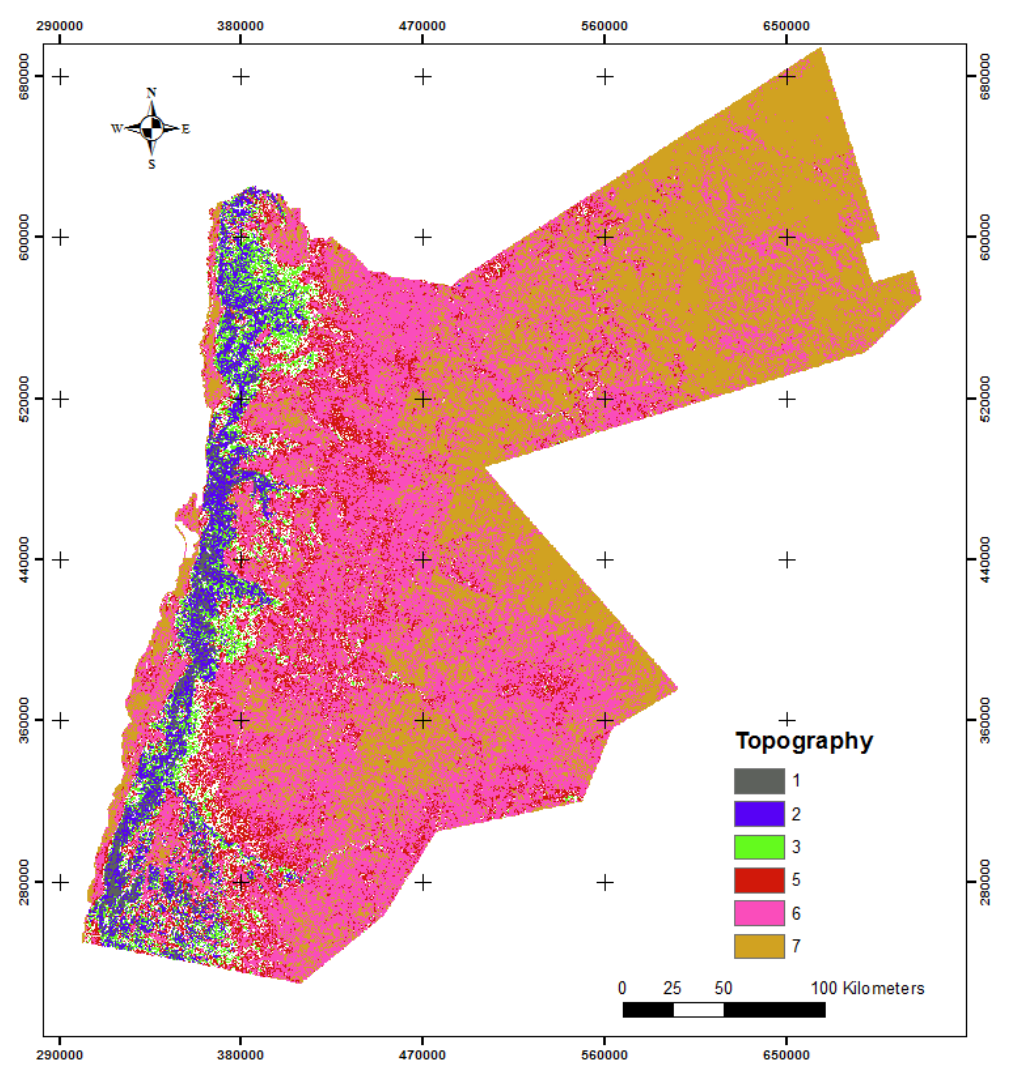

Figure 5. Topography factor values for the outcropping aquifers in Jordan.

clude: depth to water table, aquifer type, recharge availability, soil material, topography, vadose zone and hydraulic conductivity four vulnerability classes were obtained. The Jordan Valley and Wadi Araba areas were excluded because of the sensitivity of the alluvium aquifer case such as the depth to water table then which requires detailed mapping and need detailed studies.

Applying the process above as listed in Table 1, a vulnerability map can be produced that describes the ability of aquifers to be polluted as shown in Figure 6.

In this study, aquitards were excluded from the vulnerability map because this map refers to groundwater vulnerability and aquitards do not yield water. Figure 6 shows that the areas in central northern parts of the kingdom, added to some separated areas in the western parts are of higher vulnerability, this could be reasoned by the aquifer types and the soil classification in those areas, in addition to that; the depth to groundwater table in each aquifer which plays a vital role in assuming the vulnerability value.

Outcropping aquifers show a wide range of variation of vulnerability classes, ranging from very low vulnerability classes in the areas of very deep groundwater table and limited recharge up to high vulnerability classes in areas with shallow groundwater table and high potential of recharge. Figure 6 shows the variation of the groundwater vulnerability in Jordan and the variation of the vulnerability classes. Aquifer types within the study area play a major role for the vulnerability variation as shown is the alluvium areas are the higher vulnerability areas adding to that the gentle slope areas and the shallow water table.

Therefore, much care should be taken when planning projects of all types in the areas of high or medium vulnerability, whether these projects are industrial, agricultural or urban. Projects should be examined on their impacts on the groundwater resources, especially in terms of their pollution. Because, any damage of aquifers requires hundreds to thousands of years for restoration and rehabilitation.

For example, the area of Wadi As-Sir wastewater treatment plant is located in an area of medium vulnerability. This will lead to increasing potentiality of groundwater pollution in the area underlying the wastewater treatment plant and its surroundings.

Kherbit As-Samara wastewater treatment plan which is constructed in low vulnerability aquifer area but re- 


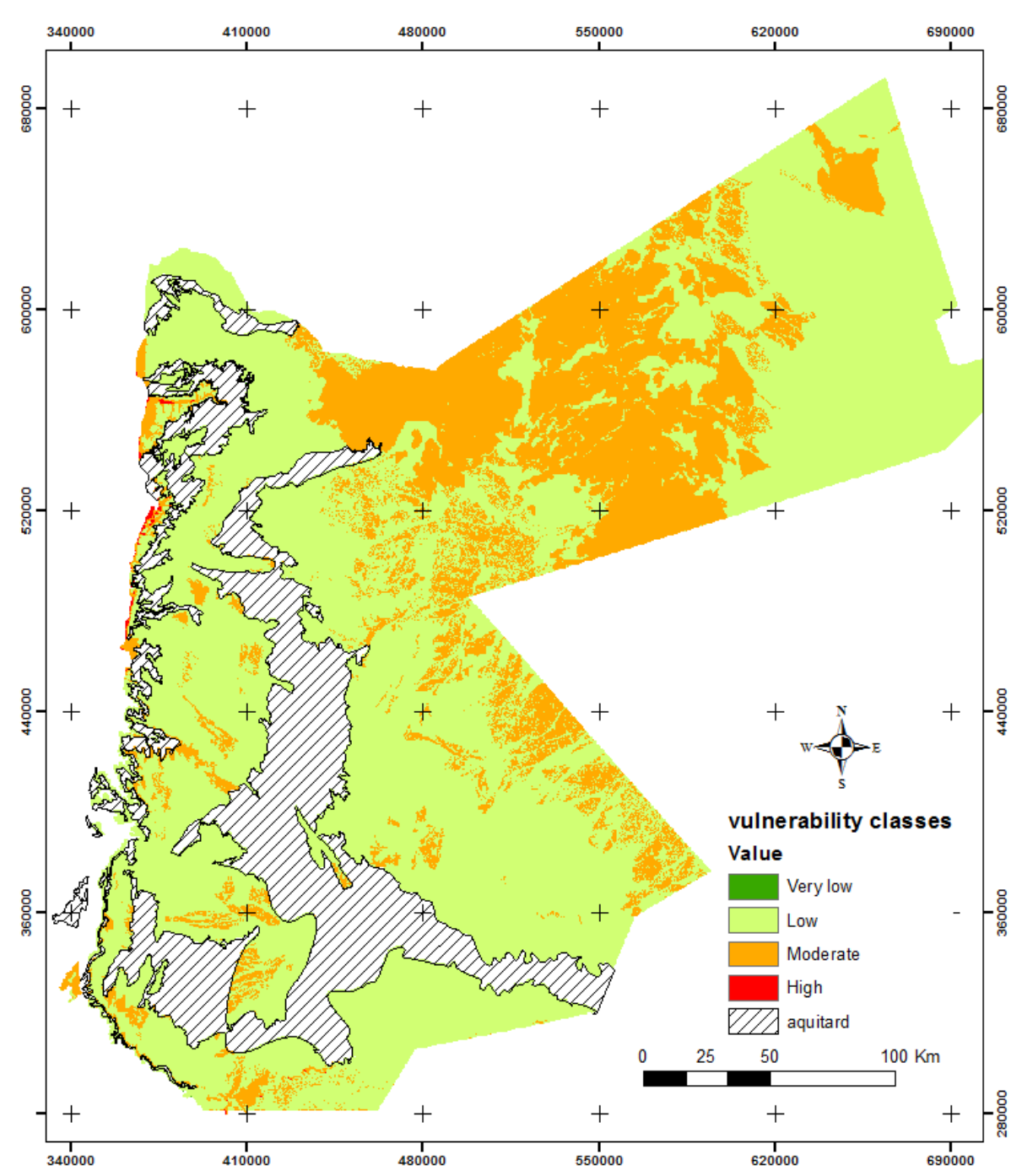

Figure 6. Groundwater vulnerability classes for the outcropping aquifers in Jordan.

charged in the area of the plant and along its effluent Wadi Dhulil causes very strong deteriorations in groundwater quality in that area.

In Disi and Sahl As Swwan areas, the groundwater is found at depths of 70 - 90 meters below ground surface. The aquifer is a free water table one; hence pollutants at ground surface can reach the ground the groundwater table and pollute the groundwater resources. Irrigation projects in the area use fertilizers and biocides which move with the return flows of irrigation downwards and contaminate the groundwater. The groundwater in that area starts showing signs of deterioration indicated by increasing groundwater salinity (irrigation return flows) and fertilizers contents.

\section{References}

[1] MWI (2002) Jordanian Ministry of Water and Irrigation. Open Files.

[2] Margat, J. (1960) Carte Hydrogéologique du Basin de Fès-Meknès au 1/100,000. Agence du Bassin Hydrauliques de Sebou, Fès.

[3] Aller, L., Bennet, T., Lehr, J.H., Petty, R.J. and Hachet, G. (1987) DRASTIC: A Standardised System for Evaluating Groundwater Pollution Potential Using Hydrogeologic Settings (EPA 600/2-87). Environmental Research Laboratory, Office of Research and Development, US Environmental Protection Agency Report, Tucson, 622.

[4] Foster, S.S.D. (1987) Fundamental Concepts in Aquifer Vulnerability, Pollution Risk and Protection Strategy. In: van 
Duijvanbooden, W. and van Waegeningh, H.G., Eds., Vulnerability of Soil and Groundwater to Pollution, Proceedings and Information No. 38 of the International Conference Held in the Netherlands, in 1987, TNO Committee on Hydrological Research.

[5] Van Stempvoort, D., Ewert, L. and Wassenaar, L. (1993) Aquifer Vulnerability Index (AVI): A GIS Compatible Method for Groundwater Vulnerability Mapping. Canadian Water Resources Journal, 18, 25-37.

Giambastiani, B.M.S. (2007) Evoluzione Idrologica ed Idrogeologica Della Pineta di san Vitale (Ravenna). Ph.D. Thesis, Bologna University, Bologna.

[6] Civita, M. (1994) Le carte della vulnerabilit`a degli acquiferi all’inquinamiento: Teoria e pratica [Contamination Vulnerability Mapping of the Aquifer: Theory and Practice]. Quaderni di Tecniche di Protezione Ambientale, Pitagora.

[7] Vias, J.M., Andreo, B., Perles, M.J. and Carrasco, F. (2005) A Comparative Study of Four Schemes for Groundwater Vulnerability Mapping in a Diffuse Flow Carbonate Aquifer under Mediterranean Climatic Conditions. Environmental Geology, 47, 586-595. http://dx.doi.org/10.1007/s00254-004-1185-y

[8] Merchant, J.M. (1994) GIS-Based Groundwater Pollution Hazard Assessment: A Critical Review of the DRASTIC Model. Photograommetric Engineering \& Remote Sensing, 60, 1117-1127.

[9] Melloul, A.J. and Collin, M. (1998) A Proposed Index for Aquifer Water-Quality Assessment: The Case of Israel's Sharon Region. Journal of Environmental Management, 54, 131-142. http://dx.doi.org/10.1006/jema.1998.0219

[10] Cameron, E. and Peloso, GF. (2001) An Application of Fuzzy Logic to the Assessment of Aquifers’ Pollution Potential. Environmental Geology, 40, 1305-1315. http://dx.doi.org/10.1007/s002540100353

[11] Al-Adamat, R.A.N., Foster, I.D.L. and Baban, S.M.J. (2003) Groundwater Vulnerability and Risk Mapping for the Basaltic Aquifer of the Azraq Basin of Jordan Using GIS, Remote Sensing and DRASTIC. Applied Geography, 23, 303324. http://dx.doi.org/10.1016/j.apgeog.2003.08.007

[12] Al-Farajat, M., Hamdan, I., Jaber, K. and Mohammed, S.H. (2005) GIS Mapping of Groundwater Vulnerability against Pollution in Amman Using DRASTIC Index. Hydrogeologie und Umwelt Heft, 33, 1-19.

[13] Baalousha, H. (2006) Vulnerability Assessment for the Gaza Strip, Palestine Using DRASTIC. Environmental Geology, 50, 405-414. http://dx.doi.org/10.1007/s00254-006-0219-z

[14] Jamrah, A., Futaisi, A.A., Rajmohan, N. and Al-Yaroubi, S. (2007) Assessment of Groundwater Vulnerability in the Coastal Region of Oman Using DRASTIC Index Method in GIS Environment. Environmental Monitoring and Assessment, 147, 125-138.

[15] Jasem, A. and Alraggad, M. (2010) Assessing Groundwater Vulnerability in Azraq Basin Area by a Modified DRASTIC Index. Journal of Water Resource and Protection, 2, 944-951. http://dx.doi.org/10.4236/jwarp.2010.211112

[16] Mohammad, A.H. (2014) New Groundwater Vulnerability Index for the Main Aquifers in Central Catchment Area in Jordan and Validation of the Results Using $\mathrm{NO}_{3}$ Concentrations Maps. World Environment, 4, 22-32.

[17] WAJ, Water Authority of Jordan (2012) Open Files.

[18] (1977) National Water Master Plan of Jordan (NWMP). Vol. III, Surface Water Resources GTZ.

[19] Vrba, J. and Zaporozec, A. (1994) Guidebook on Mapping Groundwater Vulnerability-IAH International Contributions to Hydrogeology, 16. FRG, Heise Publication, Hannover, 131 p.

[20] Engel, B.A., Navulur, K.C.S., Cooper, B.S. and Hahn, L. (1996) Estimating Groundwater Vulnerability to Non-Point Source Pollution from Nitrates and Pesticides on a Regional Scale. In: Kovar, K. and Nachtnebel, H.P., Eds., Application of Geographic Information Systems in Hydrology and Water Resources Management, IAHS Press, IAHS Publication, Wallingford, 521-526. http://www.iahs.info/redbooks/235.htm

[21] Knox, R.C., Sabatini, D.A. and Canter, L.W. (1993) Subsurface Transport and Fate Processes. Lewis Publishing, Boca Raton.

[22] Fortin, M., Thomson, K.P.B. and Edwards, G. (1997) The Role of Error Propagation for Integrating Multisource Data within Spatial Models: The Case of the DRASTIC Groundwater Vulnerability Model. Earth Surface Remote Sensing Procedure SPIE Conference, London, 358-361.

[23] Fritch, T.G., McKnight, C.L., Yelderman Jr., J.C. and Arnold, J.G. (2000) An Aquifer Vulnerability Assessment of the Paluxy Aquifer, Central Texas, USA, Using GIS and a Modified DRASTIC Approach. Environmental Management, 25, 337-345. http://dx.doi.org/10.1007/s002679910026

[24] Piscopo, G. (2001) Groundwater Vulnerability Map, Explanatory Notes. Castlereagh Catchment, NSW Department of Land and Water Conservation, Australia.

http://www.dlwc.nsw.gov.au/care/water/groundwater/reports/pdfs/castlereagh_map_notes.pdf 